\begin{tabular}{|c|c|}
\hline Title & $\begin{array}{l}\text { A noikis Induction and Inhibition of Peritoneal Metastasis of Pancreatic Cancer Cells by a Nuclear Factor-k B inhibitor, } \\
(-)-\text { DHMEQ }\end{array}$ \\
\hline Author(s) & 佐藤, 正法 \\
\hline Citation & 北海道大学. 博士(医学) 甲第11596号 \\
\hline Issue Date & 2014-12-25 \\
\hline DOI & 10.14943/doctoral .k11596 \\
\hline Doc URL & http:/hdl .handle.net/2115/57776 \\
\hline Type & theses (doctoral) \\
\hline Note & $\begin{array}{l}\text { 共著: Nakanishi, Kazuaki; Haga, Sanae; Fuj jyoshi, Masato; Baba, Motoi; Mino, Kazuhiro; Yimin; Niwa, Haruki; } \\
\text { Michitakideki; Umezawa, Kazuo; Ohmiya, Y oshihiro; Kamiyama, Toshiya; Todo, Satoru; Taketomi, A kinobu; Ozaki, }\end{array}$ \\
\hline File Information & Masanori_Sato.pdf \\
\hline
\end{tabular}

Instructions for use 
学位論文

Anoikis Induction and Inhibition of

Peritoneal Metastasis of Pancreatic Cancer Cells

by a Nuclear Factor-kB inhibitor, (-)-DHMEQ

（NF-kB 阻害剤（-)-DHMEQ による

膵癌細胞のアノイキス誘導及び腹膜転移阻害)

北海 道 大 学
佐 藤 正 法




\title{
Anoikis Induction and Inhibition of Peritoneal Metastasis of Pancreatic Cancer Cells by a Nuclear Factor-kB Inhibitor, (-)-DHMEQ
}

\author{
Masanori Sato,* Kazuaki Nakanishi,* Sanae Haga, $†$ Masato Fujiyoshi,* Motoi Baba,* Kazuhiro Mino,* \\ Yimin, \\ Satoru Todo, ${ }^{* *}$ Akinobu Taketomi,* and Michitaka Ozaki $\dagger$ \\ *Department of Gastroenterological Surgery I, Hokkaido University Graduate School of Medicine, Sapporo, Hokkaido, Japan \\ $\dagger$ Laboratory of Molecular and Functional Bio-Imaging (LMFBI), \\ Hokkaido University Graduate School of Health Sciences, Sapporo, Hokkaido, Japan \\ $\$$ Department of Advanced Medicine, Hokkaido University Graduate School of Medicine, Sapporo, Hokkaido, Japan \\ $\S$ Department of Engineering Science, The University of Electro-Communications \\ Graduate School of Informatics and Engineering, Chofu, Tokyo, Japan \\ IIDepartment of Molecular Target Medicine Screening, Aichi Medical University School of Medicine, Nagakute, Aichi, Japan \\ \#Biomedical Research Institute, National Institute of Advanced Industrial Science and Technology, Tsukuba, Ibaraki, Japan \\ **St. Mary's Hospital, Kurume, Fukuoka, Japan
}

\begin{abstract}
The transcription factor nuclear factor- $\kappa \mathrm{B}(\mathrm{NF}-\kappa \mathrm{B})$ plays a crucial role in pancreatic cancer $(\mathrm{PC})$ progression. $\mathrm{NF}-\kappa \mathrm{B}$ is also involved in resistance to anoikis, a special type of apoptosis induced when cells are detached from the extracellular matrix or other cells. Anoikis resistance is related to the metastatic abilities of tumor cells; however, little is known about anoikis induction as it relates to inhibition of PC metastasis by NF- $\mathrm{KB}$ inhibitors. Here we used a specific NF- $\mathrm{KB}$ inhibitor, (-)-dehydroxymethylepoxyquinomicin (DHMEQ), to investigate anoikis induction and peritoneal metastasis suppression following NF- $\kappa B$ inhibition. We transduced Gluc, a secretory form of luciferase, into a PC cell line, AsPC-1 (AsPC-1-Gluc), for our in vivo experiments. (-)-DHMEQ induced anoikis in AsPC-1-Gluc cells as measured by cell survival assays and flow cytometry. The DNA-binding activity of p65 was enhanced immediately after cell detachment from culture dishes in ELISA assays. Some antiapoptotic proteins such as cellular inhibitor of apoptotic protein-1 were consequently upregulated on Western blots. (-)-DHMEQ prevented this increase in p65 activity and the subsequent expressions of antiapoptotic molecules. In a murine xenograft model, anoikis-resistant PC cell lines tended to metastasize to the peritoneum more than anoikis-sensitive cells, suggesting a correlation between anoikis sensitivity and peritoneal metastasis. (-)-DHMEQ successfully inhibited peritoneal metastasis of AsPC-1-Gluc cells. We monitored metastasis inhibition by ex vivo chemiluminescent detection of Gluc secreted from tumor cells into murine plasma and by in vivo imaging. Our results suggest that (-)-DHMEQ inhibited peritoneal dissemination by preventing anoikis resistance of PC cells.
\end{abstract}

Key words: Anoikis; Dehydroxymethylepoxyquinomicin (DHMEQ); Nuclear factor- $\kappa \mathrm{B}(\mathrm{NF}-\kappa \mathrm{B})$; Pancreatic cancer (PC); Peritoneal metastasis

\section{INTRODUCTION}

Pancreatic cancer (PC) is one of the deadliest neoplasms known worldwide. The 5-year survival rate of patients with PC remains as low as $6 \%$ (1). The poor prognosis of $\mathrm{PC}$ is mainly due to local tumor invasion; metastasis to distant organs such as the liver, lung, and peritoneum; and extreme resistance to chemotherapy (2-4). Thus, there exists an urgent need to develop effective methods aimed at preventing progression and metastasis of PC.
One promising candidate for a therapeutic target in $\mathrm{PC}$ is the transcription factor nuclear factor $-\mathrm{\kappa B}(\mathrm{NF}-\mathrm{\kappa B})$. $\mathrm{NF}-\kappa \mathrm{B}$ is a heterodimeric molecule that consists of five subunits: RelA/p65, c-Rel, RelB, p105/p50, and p100/ $\mathrm{p} 52$. NF- $\mathrm{\kappa B}$ regulates the expression of numerous genes/ proteins related to inflammation, proliferation, apoptosis, invasion, adhesion, angiogenesis, and chemoresistance. $\mathrm{NF}-\kappa \mathrm{B}$ expression has been reported in various malignant diseases, including PC, and numerous studies support its association with tumor progression (5-9). Furthermore,

Address correspondence to Michitaka Ozaki, Laboratory of Molecular and Functional Bio-Imaging (LMFBI), Hokkaido University Graduate School of Health Sciences, Kita-ku, Kita 12, Nishi 5, Sapporo, Hokkaido 060-0812, Japan. Tel: +81-11-706-3337; Fax: +81-11-706-3337;

E-mail: kobra0813@gmail.com 
Fujioka and his colleagues have shown that inhibition of constitutively active NF- $\mathrm{KB}$ in PC cells suppresses tumorigenesis and metastasis in vivo $(10,11)$.

Recent studies have shown that NF- $\kappa \mathrm{B}$ is also involved in anoikis resistance, which plays a crucial role in tumor metastasis (12-14). Cells normally undergo apoptosis after detachment from the ECM or neighboring cells. This cell death process, called "anoikis," acts as a barrier against cell metastasis. However, some tumor cells acquire an ability to resist anoikis and survive the route from their primary site to metastasis-target organs such as the liver, lung, and peritoneum (15). Using intestinal epithelial cells, Yan and colleagues found that cell detachment directly activates p65 and that inhibition of NF- $\kappa \mathrm{B}$ by $\mathrm{IkB} \alpha$ or pharmacological inhibitors accelerates anoikis (12). In addition, Liu et al. found that NF- $\kappa B$ delays anoikis through upregulation of the inhibitors of apoptosis protein (IAP) family, such as X-chromosome-linked inhibitor of apoptosis protein (XIAP) and cellular inhibitor of apoptosis protein-2 (cIAP-2) (13). Results of the study by Yawata et al. indicated a correlation between the acquisition of anoikis resistance and the enhancement of peritoneal dissemination of gastric cancer cells (16). Peritoneal dissemination is one of the representative forms of metastasis of PC (17). Based on these results, we hypothesized that an $\mathrm{NF}-\kappa \mathrm{B}$ inhibitor could suppress anoikis resistance in PC cells, resulting in inhibition of peritoneal metastasis.

Dehydroxymethylepoxyquinomicin (DHMEQ), a $\mathrm{NF}-\kappa \mathrm{B}$ inhibitor, is a derivative of the antibiotic epoxyquinomicin C. After chiral separation, (-)-DHMEQ was shown to be a more potent inhibitor than (+)-DHMEQ. DHMEQ inhibits both induced and constitutively active $\mathrm{NF}-\kappa \mathrm{B}$, as well as the canonical and noncanonical pathways of NF- $\kappa B$ activation (18). A recent study has suggested that DHMEQ inhibits NF- $\kappa \mathrm{B}$ activity by binding to RelA/p65, c-Rel, and RelB (19). DHMEQ has been shown to have tumor-suppressive effects on several solid tumors and leukemia in vitro and in vivo (18). In addition, our previous study demonstrated that DHMEQ suppressed peritoneal metastasis of gastric cancer cells in murine models, likely by inhibiting tumor cell adhesion to the peritoneum via repression of integrin expression (20).

In the present study, we showed that specific inhibition of NF- $\kappa \mathrm{B}$ suppressed peritoneal dissemination of PC cells at least partly by prevented anoikis resistance.

\section{MATERIALS AND METHODS}

\section{Cell Culture}

The human PC cell lines AsPC-1, BxPC-3, HPAC, and MPanc96 were obtained from ATCC. Cell lines were maintained in RPMI-1640 culture medium supplemented with $10 \%$ FBS, 100 units $/ \mathrm{ml}$ penicillin, and $100 \mu \mathrm{g} / \mathrm{ml}$ streptomycin. All cells were cultured in a humidified incubator containing $5 \% \mathrm{CO}_{2}$ in air at $37^{\circ} \mathrm{C}$.

\section{Reagents}

(-)-DHMEQ, synthesized as previously described (21), was dissolved in DMSO and then mixed with diluents for each experiment. Poly(2-hydroxyethyl methacrylate) (poly-HEMA) was purchased from Sigma (St. Louis, MO, USA). Antibodies were obtained from the following commercial sources: anti-XIAP, cIAP-1, cIAP-2, cyclin D1, caspase-3, caspase-9, FLICE-inhibitory protein (FLIP), B-cell lymphoma-extra large (Bcl-XL), B-cell lymphoma 2-associated X protein (Bax), cleaved caspase-3 (CC3), and GAPDH (Cell Signaling Technology, Beverly, MA, USA); and anti-Ki-67 antibody (DAKO, Glostrup, Denmark). 3-(4,5-Dimethyl-2-thiazolyl)-2,5-diphenyl-2H-tetrazolium bromide (MTT) and calcein-AM (Cell Counting Kit-F) were purchased from Dojindo (Kumamoto, Japan).

\section{Animals}

Six-week-old female BALB/c nu/nu mice were purchased from CLEA Japan, Inc. (Tokyo, Japan). Mice were maintained under specific pathogen-free conditions in laminar-flow benches and were allowed to adapt to the environment for 1 or 2 weeks before experiments. All procedures involving animals and their care were approved by the Ethics Committee of Hokkaido University and were conducted under institutional and Japanese governmental guidelines for animal experiments.

\section{Establishment of AsPC-1-Gluc and Substrate Preparation}

For the quantitative evaluation of tumor volume and dissemination in vivo, we applied Gluc, a secretory form of luciferase isolated from the marine copepod, Gaussia princeps $(22,23)$, to AsPC-1 cells. A vector carrying cassettes expressing a Gluc gene with a CMV promoter and a neomycin resistance gene with an SV40 promoter (New England BioLabs, Ipswich, MA, USA) was linearized with the restriction enzymes $S s p$ I and PciI. AsPC-1 cells were transfected with this vector by using FuGENE HD Transfection Reagent (Roche, Basel, Switzerland) according to the manufacturer's instructions. Stably transfected cells were selected in $400 \mu \mathrm{g} / \mathrm{ml} \mathrm{G418}$ (Sigma) for approximately 3 weeks, cloned with cloning rings, and expanded to create monoclonal cell lines. The established cell line, AsPC-1-Gluc, was cultured in RPMI-1640 supplemented with 10\% FBS, 100 units/ml penicillin, $100 \mu \mathrm{g} / \mathrm{ml}$ streptomycin, and $100 \mu \mathrm{g} / \mathrm{ml} \mathrm{G} 418$. Coelenterazine, a substrate of Gluc, was synthesized as described previously (24) and dissolved in $99.5 \%$ ethanol and $0.0375 \% \mathrm{HCl}$ at a concentration of $1 \mathrm{mg} / \mathrm{ml}$ or $10 \mathrm{mg} / \mathrm{ml}$ as a stock solution and stored at $80^{\circ} \mathrm{C}$. The stock solution was diluted in diluting buffer $(0.1 \mathrm{M}$ Tris- $\mathrm{HCl}$ buffer, $\mathrm{pH} 7.4$, containing 0.3 M sodium L-ascorbate) for in vitro or ex vivo experiment or in PBS for in vivo studies before use. 


\section{Correlation Between Number of AsPC-1-Gluc Cells and Secreted Gluc Activity}

AsPC-1-Gluc cells were seeded in a 96-well microplate at varying cell densities $(n=4)$ and incubated overnight. Culture media were replaced by RPMI-1640 without FBS, and $1 \mu \mathrm{l}$ of the supernatant was mixed in $50 \mu \mathrm{l}$ of the diluting buffer $24 \mathrm{~h}$ later. Next, $50 \mu \mathrm{l}$ of $10 \mu \mathrm{M}$ coelenterazine was added, and chemiluminescence was measured for 10 s by using a GloMax 20/20n Luminometer (Promega, Fitchburg, WI, USA).

\section{Subcutaneous Xenograft Mice Model \\ and Correlation Between Tumor Volume \\ and Gluc Activity in Mice Plasma}

AsPC-1-Gluc cells $\left(5 \times 10^{6}\right)$ were harvested from subconfluent cultures, washed with PBS, resuspended in a mixture of $50 \mu \mathrm{l}$ of PBS and $50 \mu \mathrm{l}$ of Matrigel (growth factor reduced; BD Biosciences, Bedford, MA, USA), and subcutaneously injected into the right flank of nude mice $(n=5)$. A small amount of blood was collected from the tail vein with heparinized microhematocrit capillary tubes every 3 or 4 days and centrifuged at 12,000 rpm for $5 \mathrm{~min}$. Subsequently, $1 \mu \mathrm{l}$ of plasma was mixed with $100 \mu \mathrm{l}$ of diluting buffer containing $5 \mu \mathrm{M}$ of coelenterazine, and luminescence was measured with a luminometer as described above (Gluc plasma assay). The size of the subcutaneous tumor was measured at the time of blood draw. The following formula was used to calculate tumor volumes:

$$
\begin{gathered}
\text { Tumor volume }=(\text { shorter diameter })^{2} \\
\times(\text { longer diameter }) \times 0.5
\end{gathered}
$$

\section{Peritoneal Metastasis Model}

AsPC-1-Gluc cells $\left(1 \times 10^{7}\right)$ were washed with PBS, resuspended in $500 \mu \mathrm{l}$ of RPMI-1640, and injected into nude mice intraperitoneally $(n=5)$. Whole tumor volume was assessed by Gluc plasma assay. Intraperitoneal (IP) tumor dissemination was monitored with in vivo imaging according to the following method: $100 \mu \mathrm{g}$ of coelenterazine was diluted in $200 \mu \mathrm{lPBS}$ and administered to mice by IP injection, and luminescent images were acquired using a Photon IMAGER Hu (Biospace Lab, Paris, France) with 2 min of exposure. All imaging procedures were performed under anesthesia with isoflurane (Abbott Japan, Tokyo, Japan). Mice were sacrificed at day 30, and whole tumor volume was measured according to the formula described above.

\section{Proliferation Assay}

To study the growth inhibitory effect of (-)-DHMEQ in PC cells, we performed MTT assays. AsPC-1-Gluc cells $\left(1 \times 10^{4} /\right.$ well $)$ were seeded in a 96 -well microplate and were allowed to adhere to the bottoms of the wells overnight and then treated with various concentrations of (-)-DHMEQ for $48 \mathrm{~h}$. After a 2-h incubation with $50 \mu \mathrm{g} /$ well of MTT, formazan crystals that were formed in viable cells were dissolved with $100 \mu \mathrm{l} /$ well of DMSO, and absorbance at $570 \mathrm{~nm}$ was measured using a Varioskan Flash microplate reader (Thermo Fisher Scientific, Waltham, MA, USA). Cell viability was calculated according to the following formula:

Cell viability $(\%)=$ absorbance of treated cells/absorbance of control cells $\times 100$

\section{Anoikis Assay}

Anoikis induction by (-)-DHMEQ was evaluated as described (25) with some modifications, including usage of poly-HEMA-coated plates and calcein-AM. Poly-HEMA was dissolved at $40 \mathrm{mg} / \mathrm{ml}$ in $99.5 \%$ ethanol, and $50 \mu \mathrm{l}$ of the solution was pipetted in each well of a 96-well microplate and dried. AsPC-1-Gluc cells $\left(1 \times 10^{4} /\right.$ well $)$ were incubated with various concentrations of (-)-DHMEQ in a poly-HEMA-coated plate for $48 \mathrm{~h}$. Cell Counting Kit F was diluted to $1: 20$ in PBS; $10 \mu \mathrm{l}$ of the solution was added, and fluorescence (excitation: $490 \mathrm{~nm}$, emission: $515 \mathrm{~nm}$ ) was measured $60 \mathrm{~min}$ later using Varioskan Flash. Cell viability was calculated according to the following formula:

\section{Cell viability $(\%)=$ fluorescence of treated cells/fluorescence of control cells $\times 100$}

\section{Analysis of Cell Apoptosis by Flow Cytometry}

To investigate apoptosis induction by (-)-DHMEQ, we performed flow cytometry by using the Annexin V-FITC Apoptosis Detection Kit I (BD Biosciences) according to the manufacturer's instructions. AsPC-1-Gluc cells $\left(1.5 \times 10^{6} / \mathrm{dish}\right)$ were grown in $60-\mathrm{mm}$ dishes during adherent culture conditions or in poly-HEMA-coated dishes during suspension culture conditions and were treated with $0.08 \%$ DMSO or $40 \mu \mathrm{g} / \mathrm{ml}$ of (-)-DHMEQ for 48 h. EDTA (Life Technologies, Carlsbad, CA); 1 mM, was added to culture media for suspension cultures to inhibit cell-cell contacts. After treatment, $1 \times 10^{5}$ cells were suspended in $100 \mu \mathrm{l}$ of binding buffer and incubated with $5 \mu \mathrm{l}$ of Annexin V-FITC and $5 \mu \mathrm{l}$ of propidium iodide (PI) for $15 \mathrm{~min}$ at room temperature in the dark. Fluorescence was measured with a FACSCalibur ${ }^{\mathrm{TM}}$ flow Cytometer (BD Bioscience). Data were analyzed using FlowJo software (Tree Star, Inc., Ashland, OR, USA). Early apoptotic cells were defined as Annexin V positive and PI negative, whereas late apoptotic or necrotic cells were defined as Annexin V positive and PI positive.

\section{p65 DNA Binding Assay}

Nuclear extracts were prepared from AsPC-1-Gluc cells grown in suspension culture in poly-HEMA dishes at 0, 6, 12, and $24 \mathrm{~h}$ after detachment, by using the Nuclear Extract Kit (Active Motif, Carlsbad, CA, USA) according to the manufacturer's instructions. Nuclear samples 
from cells treated with $0.08 \%$ DMSO or $40 \mu \mathrm{g} / \mathrm{ml}$ of (-)-DHMEQ for $3 \mathrm{~h}$ in adherent or suspension cultures were also prepared. p65 DNA binding of each sample was assessed by using the TransAM Kit (Active Motif) as described in the manufacturer's instructions. Each experiment was performed in triplicate.

\section{Western Blot Analysis}

The changes of pro/antiapoptotic molecules caused by suspension culture and/or (-)-DHMEQ were assessed with Western blot analysis. AsPC-1-Gluc cells were treated with $0.08 \%$ DMSO or (-)-DHMEQ $(40 \mu \mathrm{g} / \mathrm{ml})$ for $24 \mathrm{~h}$ in adherent or suspension culture conditions. Whole cell extracts $(20 \mu \mathrm{g} / \mathrm{lane})$ were separated by SDS-PAGE and transferred onto polyvinylidene difluoride membranes using the $\mathrm{iBlot}^{\mathrm{TM}}$ Dry Blotting System (Invitrogen). Membranes were probed with primary antibodies overnight at $4{ }^{\circ} \mathrm{C}$ and with HRP-conjugated secondary antibodies for $1 \mathrm{~h}$ at room temperature. The blots were developed using Amersham ECL Plus ${ }^{\mathrm{TM}}$ Western Blotting Detection Reagents (GE Healthcare Life Sciences, Buckinghamshire, UK), and chemiluminescence was measured using the LAS-3000 imager (Fujifilm, Tokyo, Japan). Densitometry of immunoblots was performed using ImageJ software (National Institutes of Health, MD, USA).

\section{Study of Anoikis Resistance and Peritoneal Metastasis-Forming Capabilities of PC Cells}

Anoikis induction in AsPC-1-Gluc, Mpanc96, BxPC-3, and HPAC cells in 48-h suspension culture was assessed by flow cytometry by using Annexin V-FITC and PI staining as described above. To study peritoneal metastases formation, $5 \times 10^{6}$ cells of each cell line were intraperitoneally injected into BALB/c nu/nu mice. Mice were sacrificed 28 days later, and the total volume of peritoneal metastases was calculated according to the following formula:

$$
\begin{aligned}
\text { Tumor volume } & =(\text { shorter diameter })^{2} \times(\text { longer } \\
& \text { diameter }) \times 0.5
\end{aligned}
$$

The tumor nodule formed at injection site was excluded from our measurement. Each group included six mice.

\section{Evaluation of the Inhibitory Effect of (-)-DHMEQ on Peritoneal Metastasis}

AsPC-1-Gluc cells $\left(5 \times 10^{6}\right) / 250 \mu$ RPMI-1640 medium were transplanted to the peritoneal cavity of nude mice on day 1. Next, DMSO solution of (-)-DHMEQ was diluted in $0.5 \%$ carboxymethylcellulose for in vivo use. Vehicle or (-)-DHMEQ $(10 \mathrm{mg} / \mathrm{kg}$ or $20 \mathrm{mg} / \mathrm{kg})$ was intraperitoneally injected into nude mice twice a day, immediately after tumor cell inoculation. Each treatment group included six mice. Tumor volume was assessed by Gluc plasma assay, and tumor distribution in the peritoneal cavity was evaluated by in vivo imaging. On day 26 , mice were sacrificed, and the total volume of disseminated tumor nodules was measured as described above. Tumor tissue samples were fixed in $10 \%$ phosphate-buffered formalin solution and used for H\&E staining or immunohistochemistry using anti-Ki-67 and -CC3 antibodies for assessment of proliferation and apoptosis of tumor tissue, respectively $(26,27)$. Ki-67 and CC3 staining was performed using standard protocols. The number of nuclei stained positive for $\mathrm{Ki}-67$, or CC3, was counted in three representative regions of the tumor. Then, the Ki-67 or CC3 labeling index (LI) was calculated according to the following formula:

$\mathrm{Ki}-67$ or CC3 LI $(\%)=($ number of $\mathrm{Ki}-67$ or CC3-labeled cells/total number of cells $) \times 100$

\section{Statistical Analysis}

Correlations between two variables were evaluated with Pearson correlation coefficient. Differences between two groups were assessed using the Student's $t$ test. Multiple group comparisons were performed using one-way ANOVA with a post hoc test, Dunnett test, or Tukey-Kramer test for subsequent individual group comparisons. Comparisons between sequential data sets, such as Gluc activities of different treatment groups, were performed using one-way repeated measures ANOVA. A value of $p<0.05$ was considered significant.

\section{RESULTS}

\section{Establishment of Luciferase-Secreting} PC Cells and Animal Models

We established AsPC-1-Gluc cells, a PC cell line secreting luciferase. By adding coelenterazine to conditioned

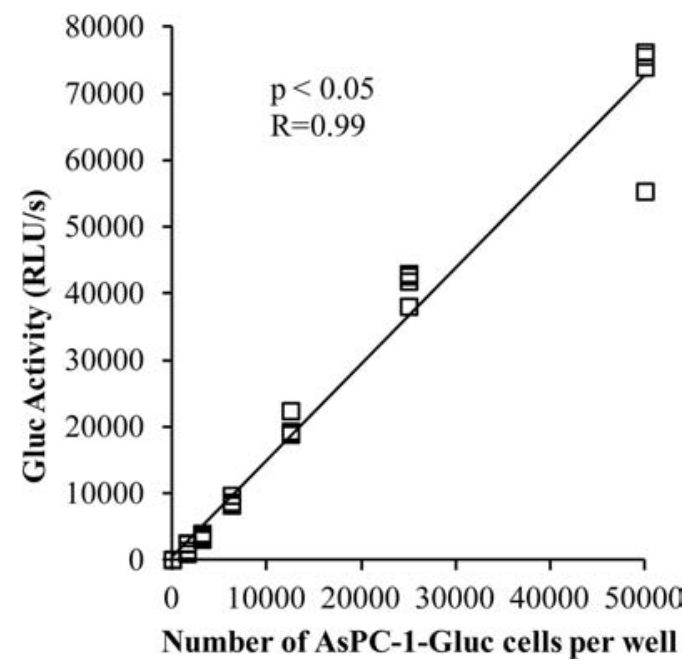

Figure 1. The correlation between the number of AsPC-1-Gluc cells and secreted Gluc activity was evaluated using Pearson correlation coefficient $(n=4)$. $R$, correlation coefficient. 
medium for AsPC-1-Gluc cells, we were able to measure luminescent activities of Gluc secreted from cells, indicating live AsPC-1 cells. The emitted photons and the number of cells showed a significant correlation $(p<0.05)$ (Fig. 1), demonstrating that the activity of secreted Gluc is a good marker of live cells. Additionally, the subcutaneous tumor size in each mouse strongly correlated with the signal intensity of plasma Gluc activity $(p<0.05$, correlation coefficient: $R=0.90 \pm 0.06$ ) (Fig. 2 A, B). In the mouse peritoneal metastasis model, we evaluated IP dissemination of tumor cells by using in vivo imaging, by directly injecting the substrate into the mice (Fig. 2C) and monitored the total amount of metastatic tumors by using the Gluc plasma assay (Fig. 2D). The Gluc activity in murine plasma at day 30 correlated well with actual tumor amounts (Fig. 2E). These results suggest that AsPC-1-Gluc is a useful tool for the quantitative evaluation of peritoneal metastases of PC cells in vivo.
A

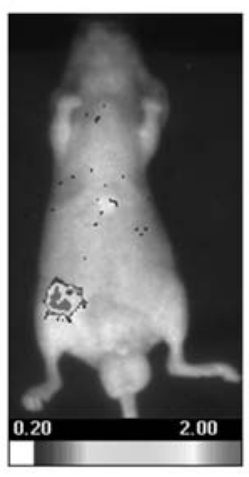

$\mathrm{C}$

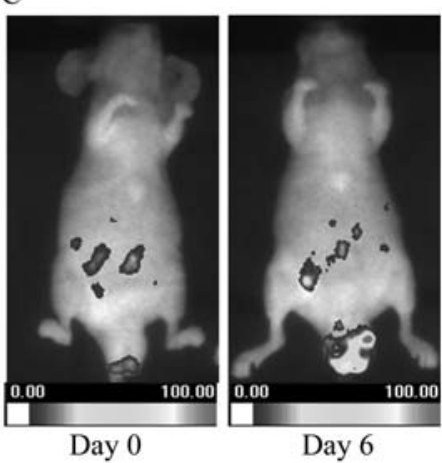

D

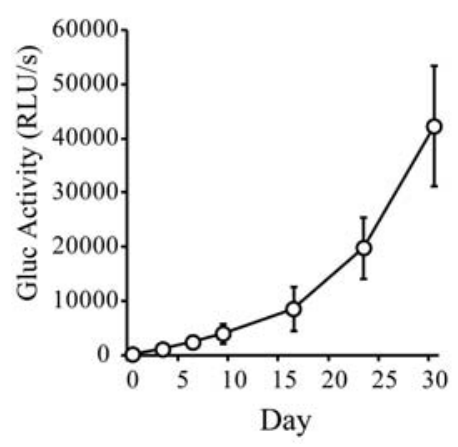

B
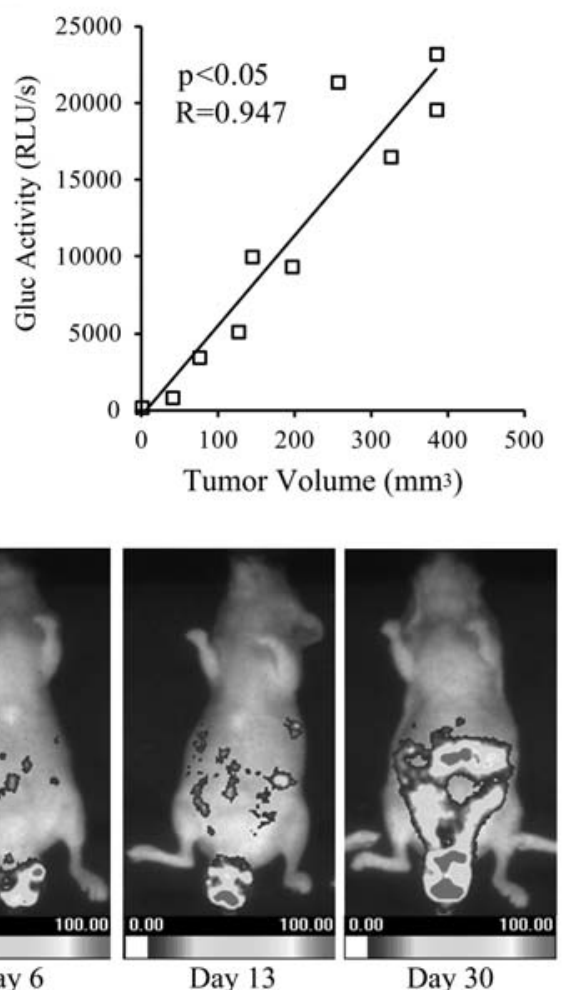

E

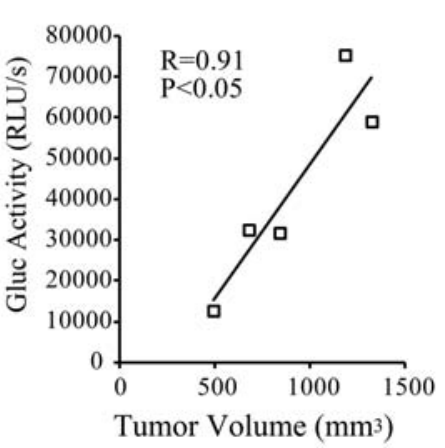

Figure 2. Murine models of AsPC-1-Gluc and bioluminescent monitoring of tumor volume and dissemination. (A) AsPC-1-Gluc cells were subcutaneously inoculated into BALB/c nu/nu mice $(n=5)$. Coelenterazine was injected intravenously, and chemiluminescence was monitored with an in vivo imaging system. (B) Correlation between the subcutaneous tumor volume and Gluc activity in mouse plasma. A result of a representative mouse is shown. (C) Peritoneal metastasis model of AsPC-1-Gluc. (D) Results of Gluc plasma assays of nude mice with peritoneal metastases of AsPC-1-Gluc cells. Error bars represent SEM. (E) Correlation between IP tumor volume and Gluc activity in mouse plasma was evaluated with Pearson correlation coefficient. 
Anoikis Induction in PC Cells by (-)-DHMEQ

Although (-)-DHMEQ inhibited the survival of both adherent and suspended AsPC-1-Gluc cells in a dose-dependent manner, the effect was stronger in suspension culture (Fig. 3A). AsPC-1-Gluc cells grown in suspension showed only a minor fraction of apoptotic cells in flow cytometric analysis; however, apoptosis was strongly enhanced when cells were incubated with $40 \mu \mathrm{g} / \mathrm{ml}$ (-)-DHMEQ (Fig. 3B). This proapoptotic effect by (-)-DHMEQ was less pronounced in adherent culture.

\section{Induction of p65 DNA-Binding Activity in Suspension} Culture and Suppression by (-)-DHMEQ

The DNA-binding activity of p65 in AsPC-1-Gluc cells was temporally enhanced in suspension culture, peaking at $3 \mathrm{~h}$ after detachment of cells, and gradually recovering to the same level as that observed in adherent culture (Fig. 4A). However, (-)-DHMEQ completely suppressed this suspension-induced p65 activity (Fig. 4B).

\section{Effect of Suspension Culture and (-)-DHMEQ on a Panel of Apoptosis-Related Proteins}

Changes in the expressions of pro- or antiapoptotic proteins were assayed by Western blot analysis (Fig. 4C, D). Expression of some antiapoptotic proteins such as cIAP-1, cIAP-2, or FLIP increased after activation of $\mathrm{p} 65$ by cell detachment. (-)-DHMEQ inhibited this upregulation of prosurvival molecules, especially cIAP-1 and cIAP-2. The expression of XIAP, an important caspase inhibitor, was reduced by cell detachment or incubation with (-)-DHMEQ and was greatly downregulated in the presence of both. Cyclin D1, also reported to be involved in anoikis resistance (28), was barely detectable in AsPC1-Gluc cells grown in suspension. (-)-DHMEQ, however, showed a limited effect on the inhibition of cyclin D1 expression. Full-length caspase-3 and caspase-9 decreased the most in suspension cells with (-)-DHMEQ. The expression of Bcl-XL and Bax was not affected by either suspension culture or (-)-DHMEQ.

\section{Anoikis Resistance and Peritoneal Metastasis of PC Cell Lines}

After $48 \mathrm{~h}$ of suspension culture, the majority of AsPC-1-Gluc and MPanc96 cells were negative for both FITC and PI; however, most of the BxPC-3 and HPAC cells were positive for FITC and/or PI as determined by flow cytometry. These results suggest that AsPC-1Gluc and MPanc96 cells were anoikis resistant, whereas BxPC-3 and HPAC cells were anoikis sensitive (Fig. 5A). Furthermore, the anoikis-resistant cell lines formed significantly more peritoneal metastases than the anoikissensitive cells in vivo (Fig. 5B), indicating a possible correlation between anoikis resistance and peritoneal metastasis of PC cells.
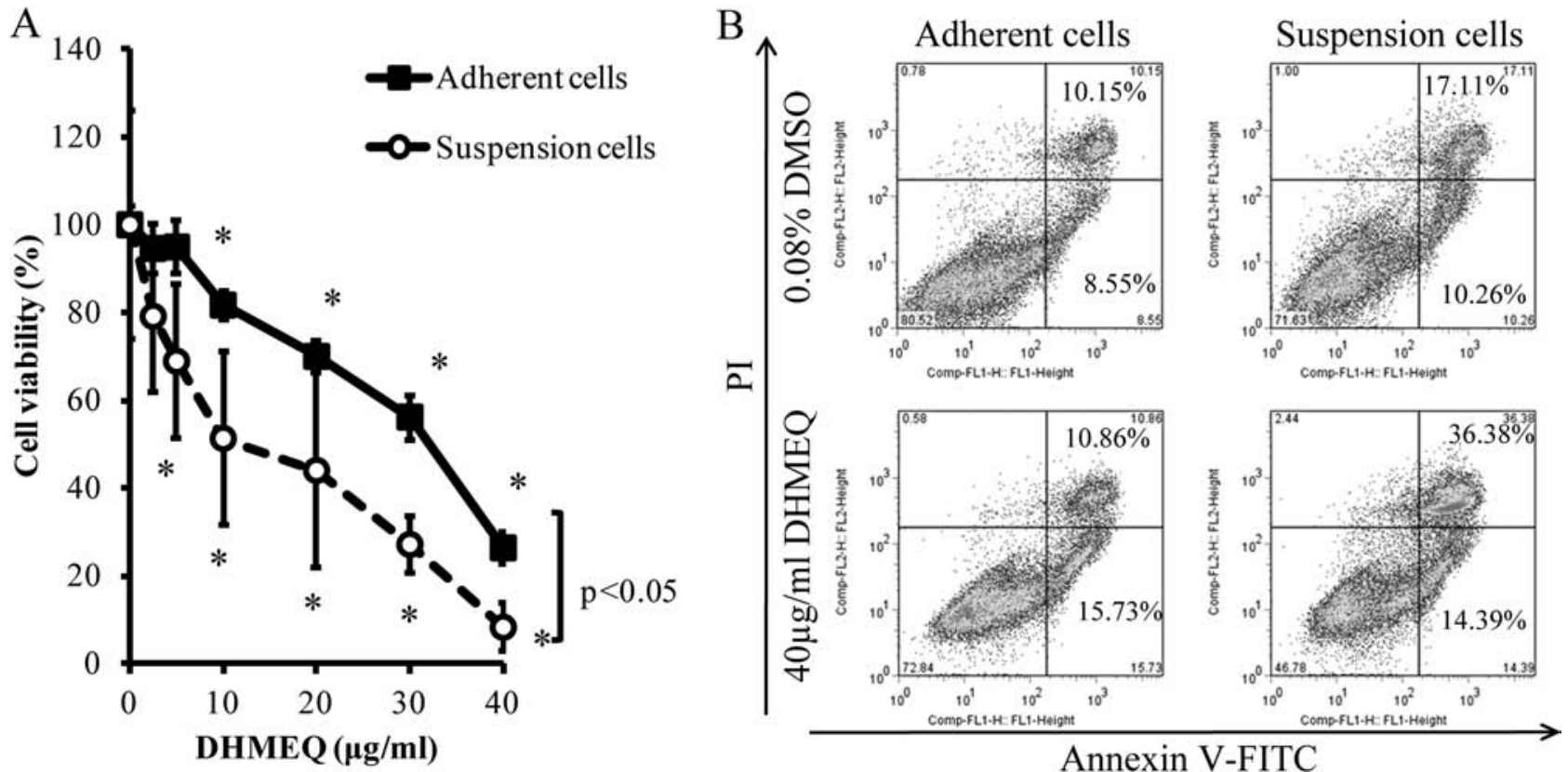

Figure 3. Anoikis induction in AsPC-1-Gluc cells by (-)-dehydroxymethylepoxyquinomicin [(-)-DHMEQ]. (A) Results of proliferation and anoikis assays. (-)-DHMEQ more effectively suppressed cell viability in suspension culture than in adherent culture $(p<0.05$, one-way repeated measures ANOVA). Error bars represent SD $(n=6) . * p<0.05$ versus control (one-way ANOVA with Dunnett test). (B) Results of flow cytometry supported anoikis induction by (-)-DHMEQ. The combination of suspension culture and (-)-DHMEQ treatment most strongly induced PC cell death. 

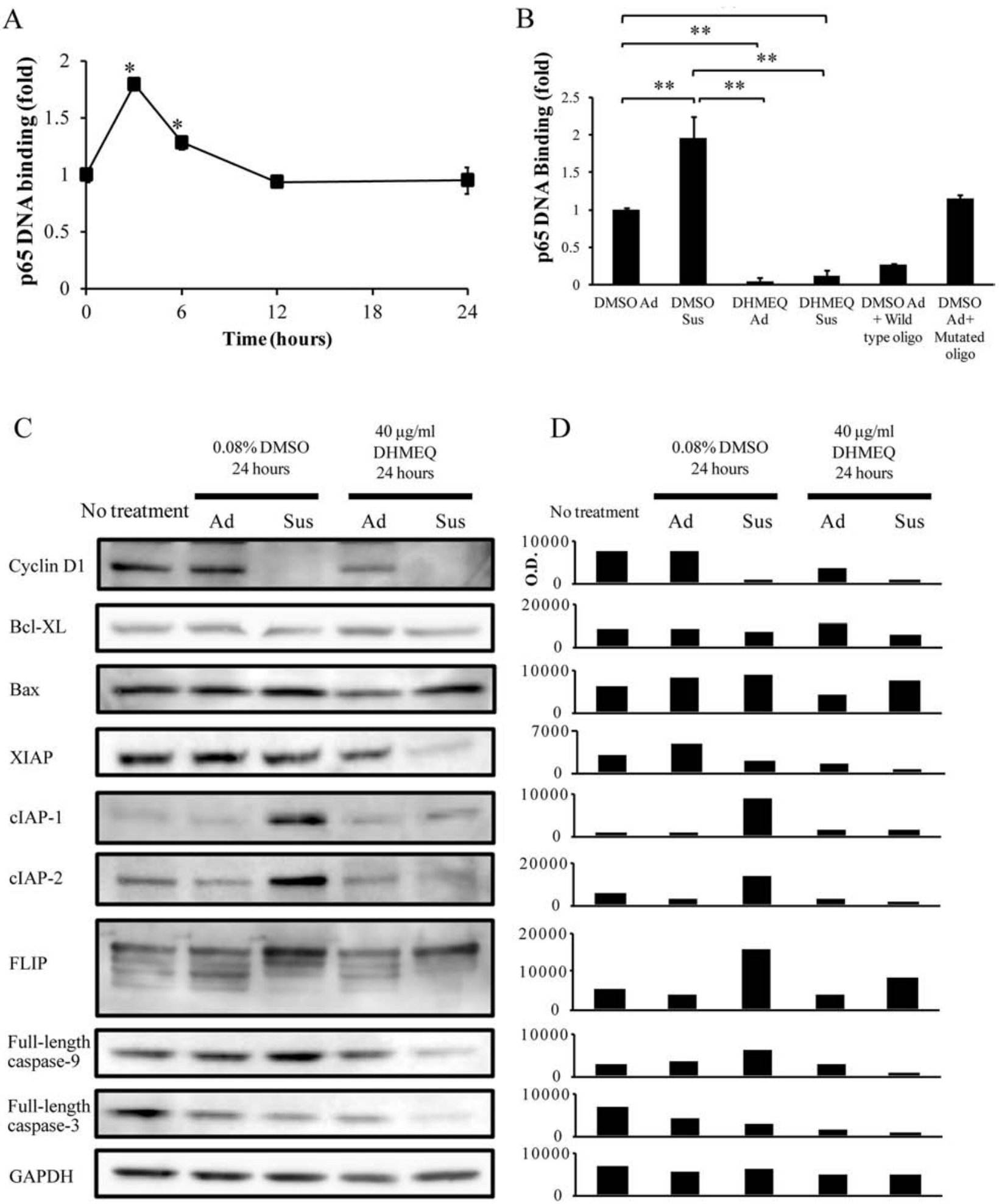

Figure 4. Molecular changes accompanying anoikis induction by (-)-DHMEQ. (A) Changes in DNA binding of p65 in AsPC-1-Gluc cells caused by suspension culture $(n=3)$. ${ }^{*} p<0.05$ versus $0 \mathrm{~h}$ (one-way ANOVA with Dunnett test). (B) (-)-DHMEQ completely suppressed the enhancement of DNA binding of p65 induced by suspension. Wild-type and mutated consensus oligonucleotides were added to ensure the specificity of the assay $(n=3)$. Error bars represent SD. Sus, suspension culture. Ad, adherent culture. $* * p<0.05$ (one-way ANOVA with Tukey-Kramer test). (C) Changes of apoptosis-related molecules were assessed by Western blot analysis and densitometry of immunoblots. O.D., optical density. 
A

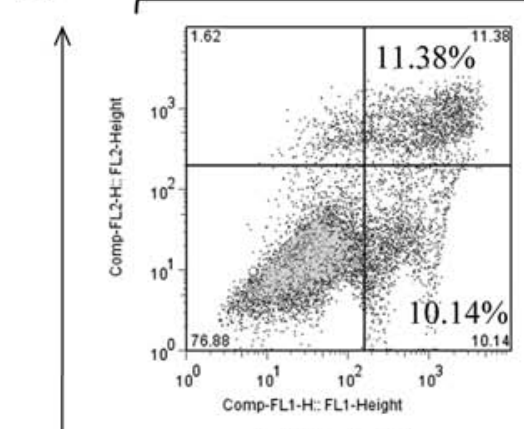

$\bar{a}$

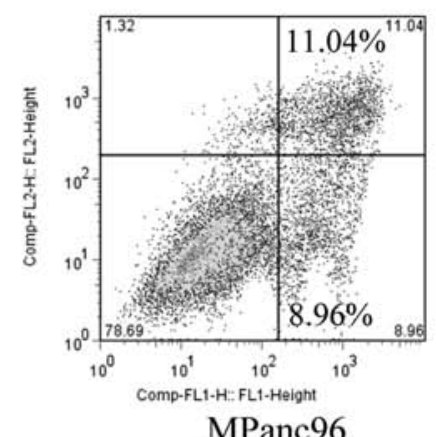

Suspension culture for 48 hours

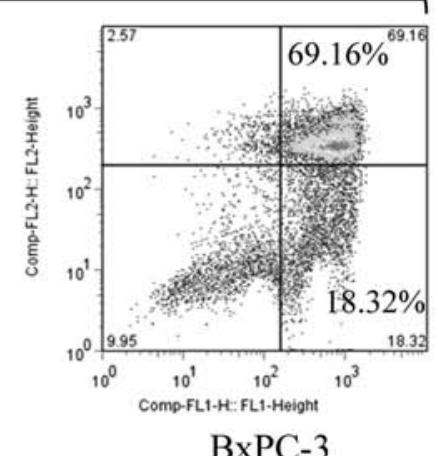

BxPC-3

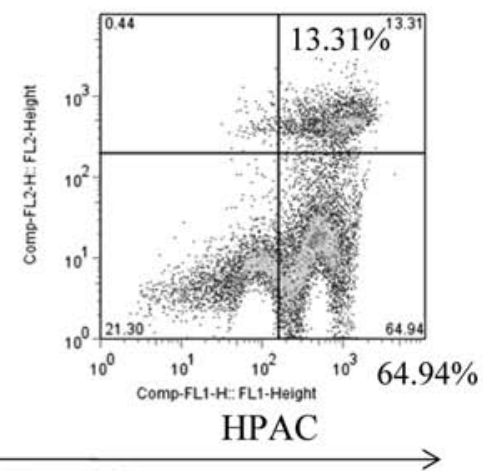

B

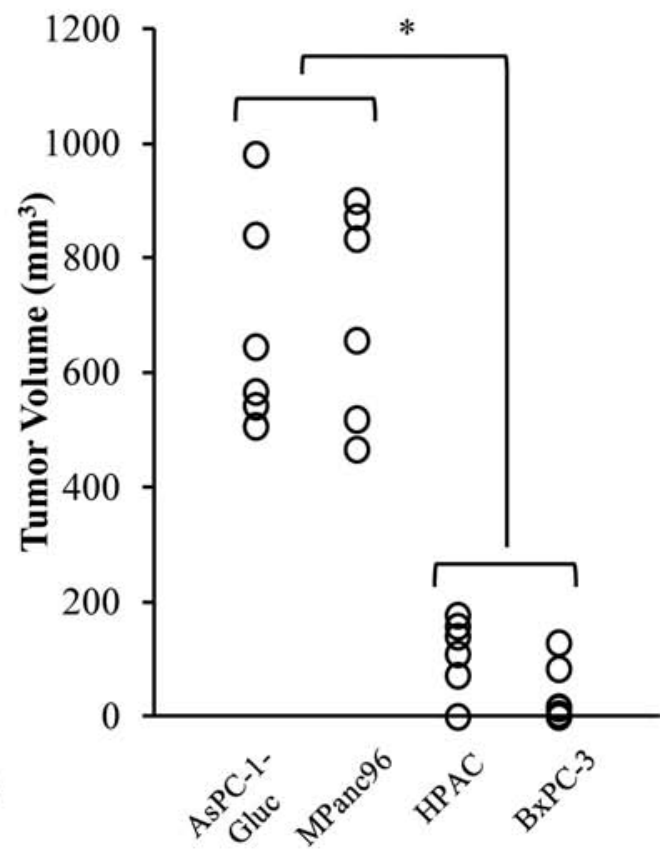

Annexin V-FITC

Figure 5. Anoikis sensitivities and peritoneal metastatic capabilities of PC cells. (A) Anoikis sensitivities of four different PC cell lines (AsPC-1-Gluc, MPanc96, HPAC, and BxPC-3) were evaluated by flow cytometry. (B) PC cells were injected intraperitoneally into nude mice, and metastases-forming capabilities were evaluated $(n=6)$. Anoikis-resistant cells (AsPC-1-Gluc, MPanc96) were more metastatic than anoikis-sensitive cells (HPAC, BxPC-3). * $p<0.05$ (Student's $t$ test).

\section{(-)-DHMEQ Suppressed Peritoneal Metastases of PC Cells In Vivo}

Based on the above results, which support a correlation between anoikis resistance, NF- $\mathrm{KB}$ activity, and peritoneal metastasis of PC cells, we conducted an in vivo study to evaluate whether (-)-DHMEQ could suppress peritoneal metastases of PC. As shown in Figure 6A, (-)-DHMEQ decreased Gluc activity in mice plasma in a dose-dependent manner. We also confirmed the inhibitory effect of (-)-DHMEQ on IP spreading of AsPC-1Gluc cells with bioluminescence imaging (Fig. 6B). The body weight loss of (-)-DHMEQ-treated mice was not observed, which suggests that (-)-DHMEQ was not toxic to the body (Fig. 6C). Those mice were sacrificed at day 26 , and macroscopic analysis showed tumor suppression by (-)-DHMEQ, similarly to the bioluminescence imaging data (Fig. 6D, E). Proliferation and apoptosis of tumor tissue samples were assessed using immunohistochemistry; however, Ki-67 or CC3 LI was not significantly different among the three treatment groups (Fig. 6E, F).

\section{DISCUSSION}

In the present study, we first demonstrated that a specific NF-KB inhibitor, (-)-DHMEQ, suppressed anoikis resistance and peritoneal metastasis of PC cells in mice. The results of proliferation assays, anoikis assays, and

\section{FACING PAGE}

Figure 6. Peritoneal metastases suppression by (-)-DHMEQ in vivo. AsPC-1-Gluc cells $\left(5 \times 10^{6} / \mathrm{mouse}\right)$ were injected into the peritoneal cavities of nude mice. These mice were treated twice a day with IP injection of vehicle, $10 \mathrm{mg} / \mathrm{kg}$, or $20 \mathrm{mg} / \mathrm{kg}$ of $(-)$-DHMEQ $(n=6)$. (A) Time course of changes of Gluc activities in mouse plasma in each group. $* p<0.05$ versus vehicle group (one-way repeated measures ANOVA). Error bars represent SEM. (B) Results of in vivo imaging. (C) Body weight of the mice of the three treatment groups. Error bars represent SEM. (D) Differences in final tumor volume among three treatment groups. ${ }^{*} p<0.05$ versus vehicle group (one-way ANOVA with Dunnett test). (E) Macroscopic (scale bar: $10 \mathrm{~mm}$ ) and microscopic (magnification: $400 \times$, scale bar: $50 \mu \mathrm{m}$ ) findings of AsPC-1Gluc tumor dissemination in the mesenteries of nude mice. Arrows indicate tumor nodules. (F) Ki-67 and CC3 LI of tissue samples. Differences of each index among three groups were evaluated using one-way ANOVA with Tukey-Kramer test. Error bars represent SD. 
A

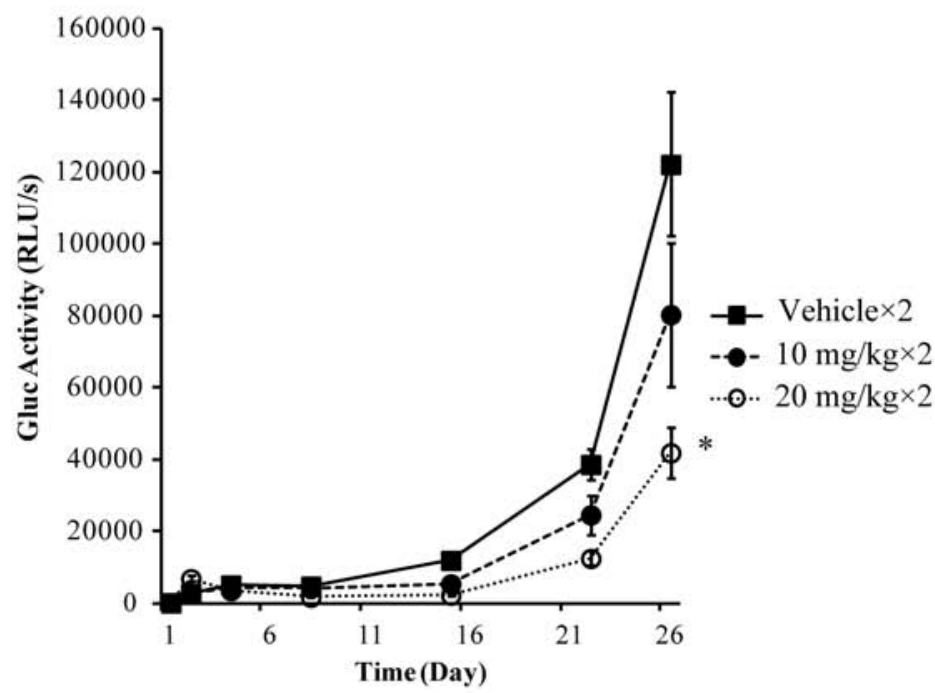

B Day 9

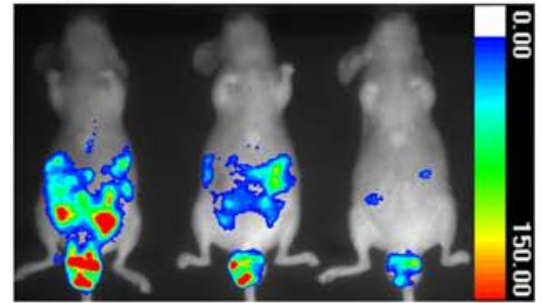

Day 18

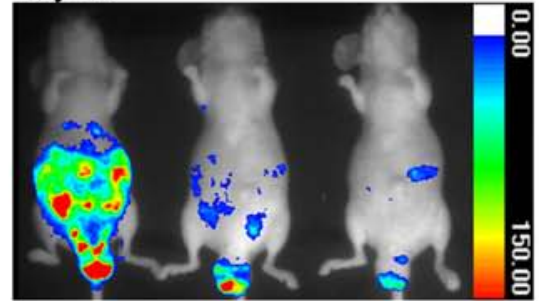

Vehicle $\times 2 \quad 10 \mathrm{mg} / \mathrm{kg} \times 2 \quad 20 \mathrm{mg} / \mathrm{kg} \times 2$

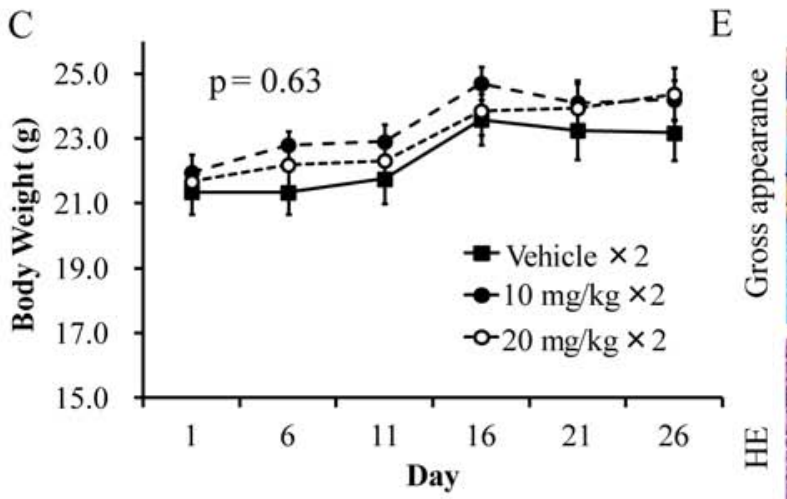

E Vehicle $\times$

$10 \mathrm{mg} / \mathrm{kg} \times 2$

$20 \mathrm{mg} / \mathrm{kg} \times 2$
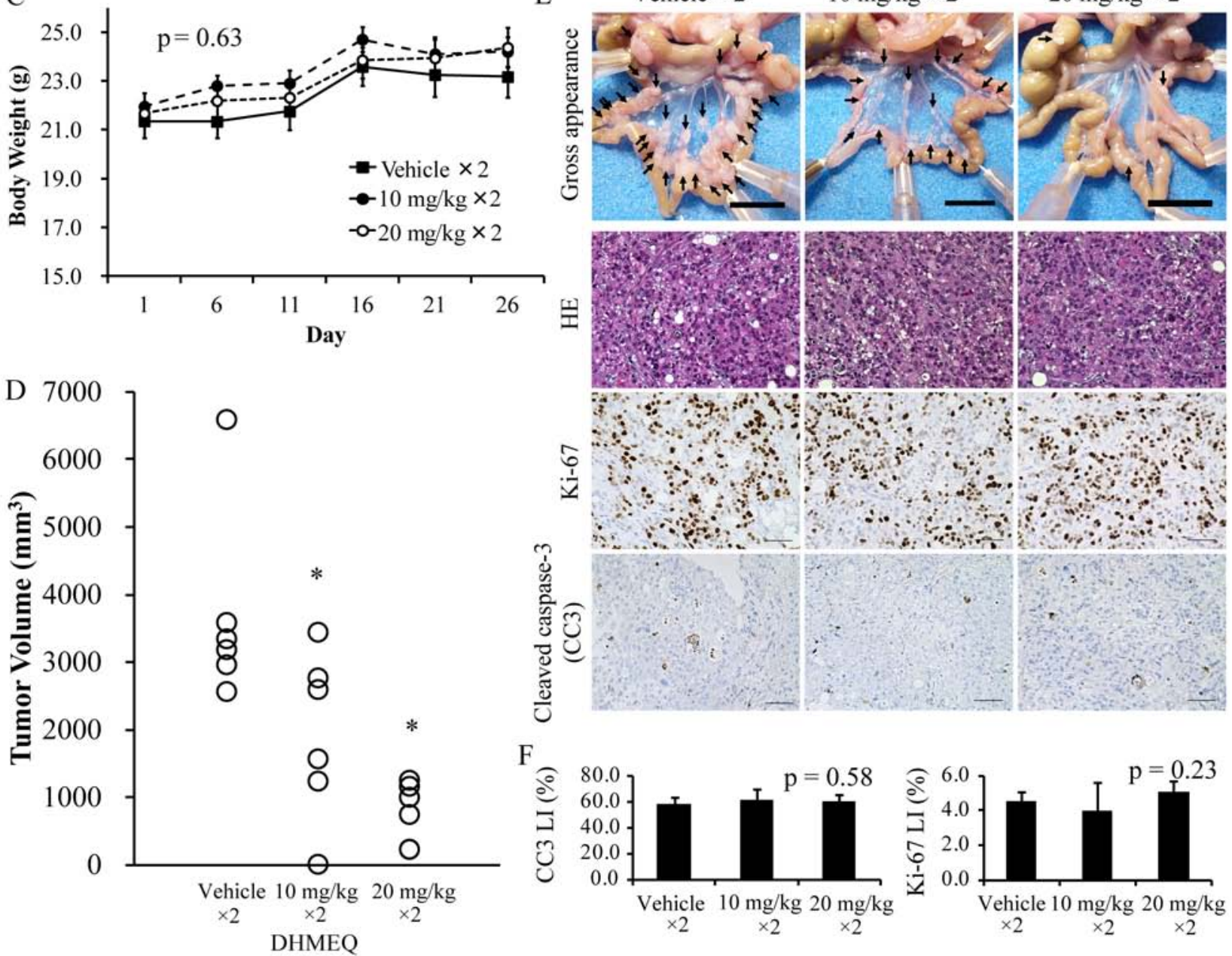
flow cytometry indicated that (-)-DHMEQ attenuated anoikis resistance of AsPC-1-Gluc cells via NF- $\mathrm{KB}$ inhibition. The dose required to induce cell death in AsPC1-Gluc cells was relatively higher than that previously reported for other tumor cells $(29,30)$. Although we did not thoroughly analyze this discrepancy in the current study, we speculate that the effective dose may depend on cell types because effective doses of (-)-DHMEQ varied among tumor cell lines in previous studies.

DNA binding of p65 was immediately elevated after AsPC-1-Gluc cells were put into suspension culture. This result is consistent with previous studies $(12,13)$. Our results of Western blot analysis showed an upregulation of cIAP-1, cIAP-2, and FLIP in suspension cultures of AsPC-1-Gluc cells. In this experiment, however, XIAP decreased upon suspension. Cyclin D1 has also been reported to play a crucial role in anoikis resistance (28), and it was almost completely repressed by suspension of AsPC-1-Gluc cells. Given these results, we speculate that cIAP-1, cIAP-2, and FLIP are involved in anoikis resistance in AsPC-1-Gluc cells, whereas XIAP and cyclin D1 play roles in anchorage-dependent survival. (-)-DHMEQ suppressed p65 activity, and the expression of the prosurvival molecules such as cIAP-1, cIAP-2, and FLIP enhanced by suspension culture, suggesting that (-)-DHMEQ induced anoikis in AsPC-1-Gluc cells, at least in part, due to inhibition of these molecules. (-)-DHMEQ also had an additive effect on repression of XIAP. Other important Bcl proteins, Bcl-XL or Bax, seem to play a minor role in anoikis induction by (-)-DHMEQ.

Finally, we demonstrated a suppressive effect of (-)-DHMEQ in peritoneal metastases of AsPC-1-Gluc cells in a mouse model, as shown in the results of our ex vivo Gluc plasma assay, in vivo luminescent imaging, and macroscopic examination at autopsy. We could not quantitatively evaluate anoikis induction in vivo because of technical difficulties; however, the results of immunohistochemistry of tumor nodules support the importance of anoikis promotion by (-)-DHMEQ in this experiment. No significant difference was observed in the Ki-67 or CC3 LI, which indicates that (-)-DHMEQ did not affect proliferation or apoptosis of adherent tumor nodules that were already metastasized to the peritoneum, and there were other mechanisms of metastasis inhibition. Collectively, we concluded that the suppression of IP spreading of AsPC-1-Gluc cells by (-)-DHMEQ was at least partly due to anoikis induction in PC cells floating in the abdominal cavities of mice. Inhibition of invasiveness may also have contributed to this effect because Suzuki et al. reported the invasion-inhibitory effect of DHMEQ on AsPC-1 cells (31).

In support of our present data, Fujiwara et al. showed that nafamostat mesilate, a synthetic serine protease, also blocks NF- $\kappa \mathrm{B}$ DNA binding and that it inhibited PC cell adhesion and invasion and promoted anoikis in PC cells in vitro (32). Furthermore, they reported that nafamostat mesilate suppressed peritoneal dissemination of AsPC-1 cells in a mouse model, although they did not describe the detailed mechanism of this anoikis promotion by nafamostat mesilate.

There are few reports that have focused on anoikis promotion as an antimetastatic mechanism of $\mathrm{NF}-\kappa \mathrm{B}$ inhibitors. Our results have provided some insight into the attenuation of anoikis resistance of PC cells as a useful approach to prevent metastasis.

ACKNOWLEDGMENTS: The authors thank Ms. Nozomi Kobayashi and Mr. Toshiyuki Watanabe (ATTO Corporation, Tokyo, Japan) for their skilled technical assistance. This study was supported by the Program for Promotion of Fundamental Studies in Health Sciences of the National Institute of Biomedical Innovation (NIBIO) and by a Grant-in-Aid for Scientific Research from the Ministry of Education, Culture, Sports, Science, and Technology of Japan (\#17390357 and \#19659317 to M.O.). The authors declare no conflicts of interest.

\section{REFERENCES}

1. Siegel, R.; Ward, E.; Brawley, O.; Jemal, A. Cancer statistics, 2011: The impact of eliminating socioeconomic and racial disparities on premature cancer deaths. CA Cancer J. Clin. 61:212-236; 2011.

2. Sharma, C.; Eltawil, K. M.; Renfrew, P. D.; Walsh, M. J.; Molinari, M. Advances in diagnosis, treatment and palliation of pancreatic carcinoma: 1990-2010. World J. Gastroenterol. 17:867-897; 2011.

3. Stathis, A.; Moore, M. J. Advanced pancreatic carcinoma: Current treatment and future challenges. Nat. Rev. Clin. Oncol. 7:163-172; 2010.

4. Xu, Q.; Zhang, T. P.; Zhao, Y. P. Advances in early diagnosis and therapy of pancreatic cancer. Hepatobiliary Pancreat. Dis. Int. 10:128-135; 2011.

5. Weichert, W.; Boehm, M.; Gekeler, V.; Bahra, M.; Langrehr, J.; Neuhaus, P.; Denkert, C.; Imre, G.; Weller, C.; Hofmann, H. P.; Niesporek, S.; Jacob, J.; Dietel, M.; Scheidereit, C.; Kristiansen, G. High expression of RelA/p65 is associated with activation of nuclear factor-kappaB-dependent signaling in pancreatic cancer and marks a patient population with poor prognosis. Br. J. Cancer 97:523-530; 2007.

6. Karin, M.; Cao, Y.; Greten, F. R.; Li, Z. W. NF-kappaB in cancer: From innocent bystander to major culprit. Nat. Rev. Cancer 2:301-310; 2002.

7. Nakanishi, C.; Toi, M. Nuclear factor-kappaB inhibitors as sensitizers to anticancer drugs. Nat. Rev. Cancer 5:297309; 2005.

8. Holcomb, B.; Yip-Schneider, M.; Schmidt, C. M. The role of nuclear factor kappaB in pancreatic cancer and the clinical applications of targeted therapy. Pancreas 36:225-235; 2008.

9. Wang, W.; Abbruzzese, J. L.; Evans, D. B.; Larry, L.; Cleary, K. R.; Chiao, P. J. The nuclear factor-kappa B RelA transcription factor is constitutively activated in human pancreatic adenocarcinoma cells. Clin. Cancer Res. 5:119$127 ; 1999$.

10. Fujioka, S.; Sclabas, G. M.; Schmidt, C.; Niu, J.; Frederick, W. A.; Dong, Q. G.; Abbruzzese, J. L.; Evans, D. B.; Baker, C.; Chiao, P. J. Inhibition of constitutive NF-kappa B 
activity by I kappa B alpha $\mathrm{M}$ suppresses tumorigenesis. Oncogene 22:1365-1370; 2003.

11. Fujioka, S.; Sclabas, G. M.; Schmidt, C.; Frederick, W. A.; Dong, Q. G.; Abbruzzese, J. L.; Evans, D. B.; Baker, C.; Chiao, P. J. Function of nuclear factor kappaB in pancreatic cancer metastasis. Clin. Cancer Res. 9:346-354; 2003.

12. Yan, S. R.; Joseph, R. R.; Rosen, K.; Reginato, M. J.; Jackson, A.; Allaire, N.; Brugge, J. S.; Jobin, C.; Stadnyk, A. W. Activation of NF-kappaB following detachment delays apoptosis in intestinal epithelial cells. Oncogene 24:6482-6491; 2005.

13. Liu, Z.; Li, H.; Wu, X.; Yoo, B. H.; Yan, S. R.; Stadnyk, A. W.; Sasazuki, T.; Shirasawa, S.; LaCasse, E. C.; Korneluk, R. G.; Rosen, K. V. Detachment-induced upregulation of XIAP and cIAP2 delays anoikis of intestinal epithelial cells. Oncogene 25:7680-7690; 2006.

14. Toruner, M.; Fernandez-Zapico, M.; Sha, J. J.; Pham, L.; Urrutia, R.; Egan, L. J. Antianoikis effect of nuclear factorkappaB through up-regulated expression of osteoprotegerin, BCL-2, and IAP-1. J. Biol. Chem. 281:8686-8696; 2006.

15. Simpson, C. D.; Anyiwe, K.; Schimmer, A. D. Anoikis resistance and tumor metastasis. Cancer Lett. 272:177-185; 2008.

16. Yawata, A.; Adachi, M.; Okuda, H.; Naishiro, Y.; Takamura, T.; Hareyama, M.; Takayama, S.; Reed, J. C.; Imai, K. Prolonged cell survival enhances peritoneal dissemination of gastric cancer cells. Oncogene 16:2681-2686; 1998.

17. Nakajima, F.; Nishimori, H.; Hata, F.; Yasoshima, T.; Nomura, H.; Tanaka, H.; Ohno, K.; Yanai, Y.; Kamiguchi, K.; Sato, N.; Denno, R.; Hirata, K. Gene expression screening using a cDNA macroarray to clarify the mechanisms of peritoneal dissemination of pancreatic cancer. Surg. Today 33:190-195; 2003.

18. Umezawa, K. Inhibition of tumor growth by NF-kappaB inhibitors. Cancer Sci. 97:990-995; 2006.

19. Watanabe, M.; Nakashima, M.; Togano, T.; Higashihara, M.; Watanabe, T.; Umezawa, K.; Horie, R. Identification of the RelA domain responsible for action of a new NF-kappaB inhibitor DHMEQ. Biochem. Biophys. Res. Commun. 376:310-314; 2008.

20. Mino, K.; Ozaki, M.; Nakanishi, K.; Haga, S.; Sato, M.; Kina, M.; Takahashi, M.; Takahashi, N.; Kataoka, A.; Yanagihara, K.; Ochiya, T.; Kamiyama, T.; Umezawa, K.; Todo, S. Inhibition of nuclear factor-kappaB suppresses peritoneal dissemination of gastric cancer by blocking cancer cell adhesion. Cancer Sci. 102:1052-1058; 2011.

21. Matsumoto, N.; Ariga, A.; To-e, S.; Nakamura, H.; Agata, N.; Hirano, S.; Inoue, J.; Umezawa, K. Synthesis of NF-kappaB activation inhibitors derived from epoxyquinomicin C. Bioorg. Med. Chem. Lett. 10:865-869; 2000.

22. Tannous, B. A.; Kim, D. E.; Fernandez, J. L.; Weissleder, R.; Breakefield, X. O. Codon-optimized Gaussia luciferase
cDNA for mammalian gene expression in culture and in vivo. Mol. Ther. 11:435-443; 2005.

23. Wurdinger, T.; Badr, C.; Pike, L.; de Kleine, R.; Weissleder, R.; Breakefield, X. O.; Tannous, B. A. A secreted luciferase for ex vivo monitoring of in vivo processes. Nat. Methods 5:171-173; 2008.

24. Kojima, S.; Maki, S.; Hirano, T.; Niwa, H.; Ohashi, M.; Tsuji, F. Improved syntheses of watasenia preluciferin (coelenterazine) and watasenia luciferin (coelenterazine disulfate), and site specific syntheses of the coelenterazine monosulfates. ITE Lett. Batter. New. Technol. Med. 2:393-397; 2001.

25. Fukazawa, H.; Mizuno, S.; Uehara, Y. A microplate assay for quantitation of anchorage-independent growth of transformed cells. Anal. Biochem. 228:83-90; 1995.

26. Li, W.; Liu, M. L.; Cai, J. H.; Tang, Y. X.; Zhai, L. Y.; Zhang, J. Effect of the combination of a cyclooxygenase-1 selective inhibitor and taxol on proliferation, apoptosis and angiogenesis of ovarian cancer in vivo. Oncol. Lett. 4:168-174; 2012.

27. Duan, W. R.; Garner, D. S.; Williams, S. D.; FunckesShippy, C. L.; Spath, I. S.; Blomme, E. A. Comparison of immunohistochemistry for activated caspase- 3 and cleaved cytokeratin 18 with the TUNEL method for quantification of apoptosis in histological sections of PC-3 subcutaneous xenografts. J. Pathol. 199:221-228; 2003.

28. Gan, L.; Liu, P.; Lu, H.; Chen, S.; Yang, J.; McCarthy, J. B.; Knudsen, K. E.; Huang, H. Cyclin D1 promotes anchorageindependent cell survival by inhibiting FOXO-mediated anoikis. Cell. Death Differ. 16:1408-1417; 2009.

29. Kikuchi, E.; Horiguchi, Y.; Nakashima, J.; Kuroda, K.; Oya, M.; Ohigashi, T.; Takahashi, N.; Shima, Y.; Umezawa, K.; Murai, M. Suppression of hormone-refractory prostate cancer by a novel nuclear factor kappaB inhibitor in nude mice. Cancer Res. 63:107-110; 2003.

30. Ohsugi, T.; Horie, R.; Kumasaka, T.; Ishida, A.; Ishida, T.; Yamaguchi, K.; Watanabe, T.; Umezawa, K.; Urano, T. In vivo antitumor activity of the NF-kappaB inhibitor dehydroxymethylepoxyquinomicin in a mouse model of adult T-cell leukemia. Carcinogenesis 26:1382-1388; 2005.

31. Suzuki, K.; Aiura, K.; Matsuda, S.; Itano, O.; Takeuchi, O.; Umezawa, K.; Kitagawa, Y. Combined effect of dehydroxymethylepoxyquinomicin and gemcitabine in a mouse model of liver metastasis of pancreatic cancer. Clin. Exp. Metastasis 30:381-392; 2013.

32. Fujiwara, Y.; Furukawa, K.; Haruki, K.; Shimada, Y.; Iida, T.; Shiba, H.; Uwagawa, T.; Ohashi, T.; Yanaga, K. Nafamostat mesilate can prevent adhesion, invasion and peritoneal dissemination of pancreatic cancer thorough nuclear factor kappa-B inhibition. J. Hepatobiliary Pancreat. Sci. 18: 731-739; 2011. 